\title{
Biodegradation of Acenaphthene Using Two Different Isolated Bacteria: Comparative Analysis and Optimization Using Artificial Neural Network
}

\author{
Dolanchapa Sikdar, Abhirupa Banerjee, Papita Das and Siddhartha Datta \\ Dept. of Chemical Engineering, Jadavpur University, Kolkata, India \\ Email: dolanchapa30@gmail.com, papitasaha@gmail.com, sdatta_che@rediffmail.com
}

\begin{abstract}
Polycyclic Aromatic Hydrocarbons are one of the toxic pollutants in nature having both carcinogenic and mutagenic effects and accumulate in the environment from industrial wastes, natural sources like volcanoes and human activities. Acenaphthene degradation efficiency of two isolated micro-organism Bacillus sp. PD5 and Halomonas sp.PD4; gram positive and gram negative bacteria were evaluated in batch experiments. The study was performed by different parameters like inoculum volume, $\mathrm{pH}$, salinity, temperature, agitation speed and a comparative analysis was carried out. The objective of this study was to compare the efficiency of the isolated organisms to degrade acenaphthene under different experimental conditions. The maximum acenaphthene degradation was found to be around $82 \%$ by Bacillus sp. PD5 and $65.25 \%$ in case of Halomonas sp.PD4. Artificial neural network was applied to estimate the maximum degradation of acenaphthene by both microorganisms and it was observed that the developed ANN model significantly satisfied the experimental results.
\end{abstract}

Keywords: Acenaphthene, Bacillus sp. PD5, Biodegradation, Halomonas sp.PD4, Polycyclic Aromatic Hydrocarbons, Artificial Neural Network (ANN).

\section{Introduction}

Contamination of soil is of great concern in today's world. Petroleum is one of the main sources of soil contamination which occurs due to leakage of oil from oil storage tanks underground or overhead, during transportation of petroleum products, from industrial processes and from abandoned oil stations or factories [1]. Polycyclic aromatic hydrocarbons compounds are mainly fused form of aromatic rings. They are solid at room temperature and are more soluble in oil than water i.e. lipophilic in nature. PAHs are mutagenic as well as carcinogenic [2]. Some of them have toxic effects. PAHs usually gain entry in our body generally by inhalation of air and are stored in kidney and liver. They also have adverse effects on plants and animals. Different sources of PAHs include incomplete combustion of coal tar, oil, gas, petroleum, volcanic eruptions, and internal combustion of engines and by-products of industries [3-6]. There are more than $100 \mathrm{PAHs}$ present in our environment out of which $16 \mathrm{PAHs}$ are very harmful as identified by the United States Environmental Protection Agency (USEPA) [7]. Generally, the low molecular weight PAHs are easily degradable. As molecular weight increases, a corresponding decrease in degradation rate has been observed [8]. The focus of this study was biodegradation of one of the polyaromatic hydrocarbons, acenaphthene. Acenaphthene is a component of coal tar, crude oil and a product of combustion of natural fires [9], which tends to be the main reason of spreading acenaphthene in the environment as a pollutant. Acenaphthene (chemical formula: $\mathrm{C}_{12} \mathrm{H}_{10}$ ) a pale yellow crystalline and hydrophobic substance has molar mass $154.21 \mathrm{~g} \cdot \mathrm{mol}^{-1}$; density: $1.024 \mathrm{~g} / \mathrm{cm}^{3}$; melting point: $93.4{ }^{\circ} \mathrm{C}\left(200.1{ }^{\circ} \mathrm{F} ; 366.5 \mathrm{~K}\right)$; boiling point : $279{ }^{\circ} \mathrm{C}\left(534{ }^{\circ} \mathrm{F} ; 552 \mathrm{~K}\right)$. Acenaphthene is widely used in industries for the production of dyes, fungicides, insecticides, pharmaceuticals, plastics [10].

Different methods are being employed to remove PAHs. A new method was used by employing Fenton reagent to enhance the degradation of PAHs process in soil [11]. Review of literature have shown the photocatalytic degradation of $\mathrm{PAHs}$ using $\mathrm{TiO}_{2}$ under UV light [12]. Destruction of few PAHs like 
acenaphthene, fluorene, anthracene and pyrene using a dc gliding arc plasma reactor was reported [13].Degradation of PAHs using microorganisms has generated interest in recent times. Biodegradation is widely accepted as it is cost effective, requires less labour, chemicals and energy, is reliable and applicable on wide scale with requirement of lesser amount of chemicals during the process [14]. Isolation of microorganisms for efficient biodegradation can be done from the contaminated sites itself. Different factors like $\mathrm{pH}$, temperature, salinity, aeration etc. closely guide this process because these parameters may influence the structure and physiology of microorganism and thereby influence the chemical and physical properties of the PAH used [15-17].

Reports showed degradation of low molecular weight PAH like naphthalene, phenanthrene by using isolated microbial strains, though a very few studies reported the degradation of acenaphthene by using bacteria. There were also reports of Bacillus sp. strains degrading pyrene [18], whereas, Halomonas strain, playing an auxiliary role, was found degrading a very low concentration of phenanthrene with metabolites of phenanthrene producing toxic substances, which accumulated in the media [19]. A study reported different PAHs like phenanthrene, fluoranthene, fluorene were degraded by Mycobacterium sp.[20-22]. Sphingomonas sp.strain A4 had shown capability of utilizing the carbon source acenaphthene and acenaphthylene [23]., Acinetobacter sp. strain AGAT-W, isolated from municipal wastecontaminated soil could degrade acenaphthene into 1-acenaphthanol, with subsequent transformation into catechol via acenaphthenequinone, naphthalene-1,8-dicarboxylic acid, 1-naphthoic acid and salicylic acid entering into tricarboxylic acid cycle (TCA) [24]. In a later study, Beijerinckia sp. strain B8/36 was found to oxidise acenaphthene to spectrum of metabolites, including 1-acenaphthenol, 1-acenaphthenone, 1,2-acenaphthenediol, acenaphthenequinone [9]. Pseudomonas sp. A4 strain was shown to have the ability to utilize acenaphthene [25] while Pseudomonas sp. was reported as using naphthalene as carbon source [26]. In earlier reports, Alcaligenes sp. was reported as bacteria using acenaphthene [27].

The objective of the present study was comparison of degradation efficiency of acenaphthene by gram negative and gram positive bacteria at varying conditions which can affect the degradation and to develop a neural network computing mathematical model to predict the degradation efficiency of these two micro-organisms using experimental results. The novelty of this work is isolation of gram negative and gram positive bacteria from two different sources of polluted field and its application for the degradation of acenaphthene present in solution. The other novelty of the work is the prediction of the degradation efficiency of these two isolated micro-organisms using artificial neural network technique.

\section{$2 \quad$ Materials and methods}

\section{$2.1 \quad$ Reagents}

The PAH treated in this study was performed using minimal media consisting of $(\mathrm{g} / \mathrm{L}): \mathrm{K}_{2} \mathrm{HPO}_{4}=0.348$, $\mathrm{KH}_{2} \mathrm{PO}_{4}=0.272, \quad \mathrm{NaCl}=4.68, \quad \mathrm{MgCl}_{2} \cdot 6 \mathrm{H}_{2} \mathrm{O}=0.2, \quad \mathrm{CaCl}_{2} . \quad 2 \mathrm{H}_{2} \mathrm{O}=0.03, \quad \mathrm{NH}_{4} \mathrm{Cl}=1.07, \quad \mathrm{KCl}=1.49$, $\mathrm{Na}_{2} \mathrm{SO}_{4}=0.43$. All the chemicals used for the preparation of minimal media were obtained from Merck (Darmstadt, Germany).

\subsection{Strain isolation and sub culturing of the organisms}

For degrading the polycyclic aromatic hydrocarbons (PAH), both the bacterial strains Bacillus sp.PD5 and Halomonas sp.PD4 were isolated and used. Halomonas sp.PD4 was isolated from soil of PAH polluted site, Petroleum Oil Industry, Durgapur, West Bengal, India and Bacillus sp. PD5 was isolated from polluted area of Bankura, West Bengal, India. The sample from the affected area was collected and serial dilution method was employed to for the isolation of pure culture of organism which could capable to degrade the acenaphthene. The sterilised agar containing acenaphthene was poured in petriplates and diluted soil sample was then added to the plates. Agar plates were incubated at $310 \mathrm{~K}$ for 24 hours in the incubator (Model: CIS -24 Plus, Remi ,India). Each of the isolated organisms was identified by various biochemical and bacteriological tests done by subculturing of each of the isolated organisms. The isolated bacteria were analysed using different biochemical test followed by 16S rRNA gene sequence [28]. 


\section{$2.3 \quad$ Media and Culture conditions}

For the enrichment of microorganisms which were capable to degrade the PAHs, the media was prepared using minimal media components and the sole carbon source used was acenaphthene. Acenaphthene was dissolved in acetone (5\%) and added to the minimal media [21] to make the final concentration of the solution as $10 \mathrm{mg} / \mathrm{L}$. For the enrichment of the isolated organisms and to analyze the result of batch study for degradation of acenaphthene, the minimal media was incubated at $310 \mathrm{~K}$ and $120 \mathrm{rpm}$ for around 2 weeks.

\subsection{Experimental conditions}

The experiments were performed using $50 \mathrm{ml}$ minimal media and acenaphthene $(10 \mathrm{mg} / \mathrm{L})$ as carbon source acenaphthene $(10 \mathrm{mg} / \mathrm{L})$. The tested factors were inoculum volume $(1 \%, 2 \%, 4 \%$ and $6 \%$ of the working volume), salinity $(0 \%, 2.5 \%, 5 \%, 7.5 \%$ and10\%), $\mathrm{pH}(6.0,7.0,8.0,9.0,10$ and 12$)$, temperature (298K, $303 \mathrm{~K}, 310 \mathrm{~K}, 313 \mathrm{~K}$ and $318 \mathrm{~K}$ ) and agitation. The samples were collected from the Erlenmeyer flask containing the inoculated media at definite interval of time and transferred to centrifuge tube and centrifuged [Remi, India , Model: PR 24] for 10mins at $10000 \mathrm{rpm}$ [29]. The supernatant of the centrifuged samples were extracted and were passed through syringe filter $(0.22 \mu \mathrm{m})$ and analysed using HPLC (Model: Series 200 HPLC, Perkin Elmer, Singapore). The biomass present in the solution was analysed using UV/Vis Spectrophotometer [Lambda 35, Perkin Elmer, Singapore].

\subsection{Mathematical Modelling using Artificial Neural Network (ANN)}

ANN model was developed using Matlab 7 in this study [30-35]. 4-layer network was developed using linear transfer function and back-propagation neural network. The input variables selected for the feed forward network were inoculum volume (\% w/w), treatment time (min), Temperature $(\mathrm{K})$ and $\mathrm{pH}$ as dependent variables. The experimental responses or output variables was denoted by $\%$ removal of acenaphthene observed in the degradation study [30-35].

\section{$3 \quad$ Results and Discussion}

The batch study was performed using both isolated organisms: Bacillus sp. PD5 (Ba) and Halomonas sp. PD4 (Ha). Different parameters mentioned before were taken into consideration and results were compared. Every experiment was performed in triplicate and the average of these values was taken into consideration in each case.

It was observed from Fig.1 that rate of degradation of acenaphthene by Ba was higher than that by $\mathrm{Ha}$ in respect of time. The reason could be greater efficiency of $\mathrm{Ba}$ in degrading acenaphthene in comparison to Ha species.



Figure 1. Graph shows comparative study of percentage degradation of acenaphthene by Bacillus sp. PD5. and by Halomonas sp.PD4.after 12 days incubation period at pH 9 at $120 \mathrm{rpm}$ speed and at 310K temperature. 


\subsection{Characterization of the isolated species}

IMVIC test results for Bacillus sp. PD5 (Ba) showed positive Voges Proskauer's, citrate utilization and glucose utilisation tests with negative results in indole, methyl red test, adonitol, arabinose, lactose, sorbitol etc. For Halomonas sp. PD 4 , only glucose utilization was positive and other biochemical test proved negative. Bacillus sp. PD5 was rod shaped gram positive bacteria whereas Halomonas sp. PD4 was rod shaped gram negative bacteria. Phylogenetic analysis of the nearly complete 16S rRNA gene sequence of strain PD5 suggested that it belonged to the member of bacillus sp. and for PD4, it was Halomonas sp. The 16sRNA gene sequence of the isolated strain were deposited in Genbank nucleotide sequence database under accession number KU901698 for Bacillus sp. PD5 and JX91241 for Halomonas sp. $P D_{4}$.

\subsection{Effect of different inoculum volumes:}

In the study, the parameter studied was different volumes of inoculum $(\% \mathrm{v} / \mathrm{v})$. Different working volume of both the organisms ( $\mathrm{Ba}$ and $\mathrm{Ha})$. (1\%/2\%/4\%/6\% of the working volume) were chosen and added to $50 \mathrm{ml}$ of minimal media with acenaphthene as sole carbon source and the study was conducted for 7 days. $\mathrm{CFU} / \mathrm{ml}$ of the inoculum volume was measured using standard procedure. The degradation of the PAH was analysed by spectrophotometric and HPLC analysis method as mentioned earlier. In case of $B a$, the maximum degradation was found using inoculum volume of $2 \%(v / v)$ and in case of $\mathrm{Ha}$, the maximum degradation of acenaphthene was found using inoculum volume $1 \%(v / v)$. So the further study was carried out by using inoculum volume $2 \%(v / v)$ for $B a$ and $1 \%$ for $H a$. But the result showed that though individually using inoculum volume $2 \%(v / v)$, both the cultureorganisms had utilised maximum substrate (acenaphthene), but $B a$ showed high rate of removal of acenaphthene than $H a$. The reason may be that both $B a$ and $H a$ could utilise acenaphthene as only carbon source but in comparison to $\mathrm{Ha}, \mathrm{Ba}$ had shown significant better result. The reason may be the production of toxic metabolites during non-specific metabolitic reactions in case of $\mathrm{Ha}$ [19] [Fig.2].

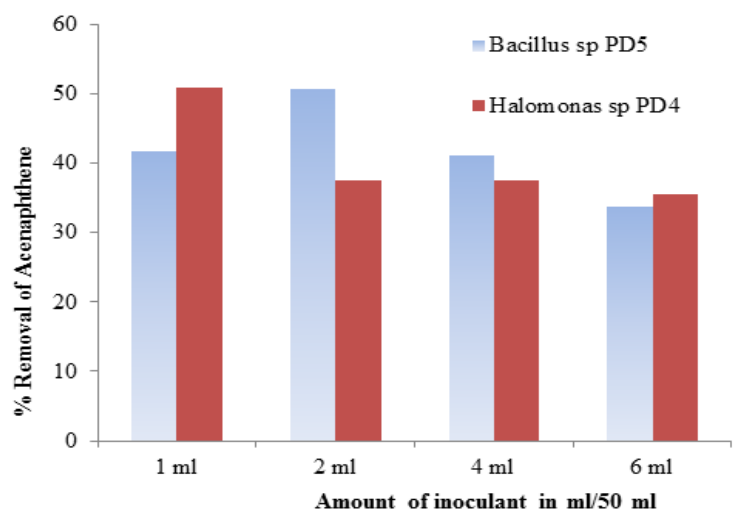

Figure 2. Effect of inoculum volume $(v / v)$ of Bacillus sp. PD5 and Halomonas sp.PD4 in degradation of acenaphthene of $10 \mathrm{mg} / \mathrm{L}$ concentration at $310 \mathrm{~K}$ temperature after 7 days.

\subsection{Effect of salinity}

The comparative study was performed on degradation of acenaphthene at different concentrations of saline (Fig 3) by using $\mathrm{Ba}$ and $\mathrm{Ha}$ individually to know the degradation efficiency of both the microorganisms at extreme saline conditions of salinity. Minimal media of different salinities $(0 \%, 1 \%, 2.5 \%$, $5 \%, 7.5 \%, 10 \%)(w / v)$ were taken and maximum percentage removal of acenaphthene detected for $\mathrm{Ba}$ was $70.439 \%$ in $\mathrm{NaCl}$ concentration using $5 \%(w / v)$, whereas in case of $\mathrm{Ha} \mathrm{PD} 4$, the maximum percentage removal of acenaphthene was found to be $74.913 \%$ using $7.5 \%(w / v) \mathrm{NaCl}$ concentration. $\mathrm{Ha}$ showed better result than $\mathrm{Ba}$ at $7.5 \%(w / v)$ saline concentration. Isolated from petroleum contaminated soil, $\mathrm{Ha}$ showed a better rate of degradation of acenaphthene at saline concentration. But 
as the saline concentration increased to $10 \% \mathrm{NaCl}$, the rate of degradation slowed down. It had been reported in literature [19] that at higher saline concentration, bacterial strain was not able to survive and as a result degradation of acenaphthene may decreased, It was also reported in literature that a single bacterial strain could not utilise PAHs at higher conditions of salinity. It may be predicted that $\mathrm{Ha}$ showed decreased rate of degradation of acenaphthene due to increased concentration of salinity $(>7.5 \%)$. A similar observation was also reported in literature and it can be suggested that salinity had influenced the degradation of acenaphthene by reducing the microbial activity or by limiting the solubility of PAHs at higher saline condition.

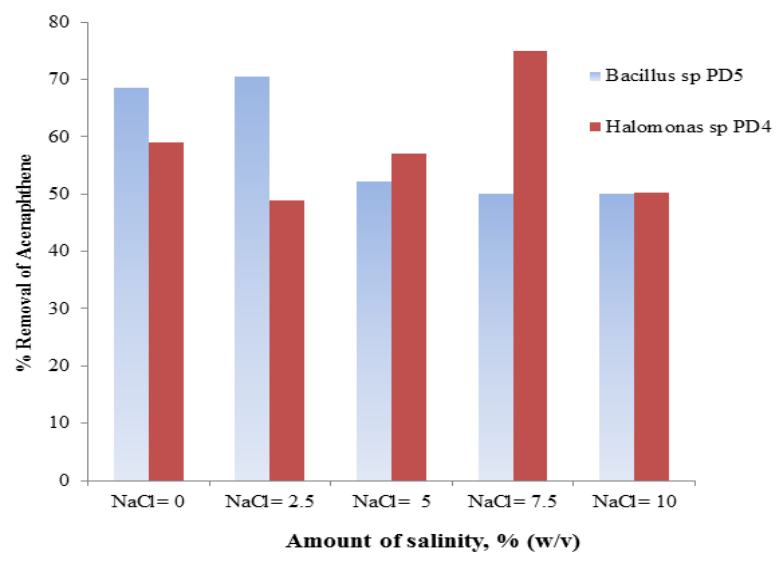

Figure 3. Comparison of degradation of acenaphthene after 7 days by using the Bacillus sp. PD5 and Halomonas sp. PD4. at various concentration of saline condition.

\subsection{Effect of $\mathrm{pH}$}

In this case, the $\mathrm{pH}$ of the minimal media varied from $\mathrm{pH} 6$ to $\mathrm{pH} 12$. The $\mathrm{pH}$ was adjusted by using 1 $\mathrm{N} \mathrm{NaOH}$ and $0.1 \mathrm{~N} \mathrm{HCl}$. The culture solution was taken in 100ml Erlenmeyer flask and was supplemented with $10 \mathrm{mg} / \mathrm{L}$ acenaphthene. $\mathrm{pH}$ was maintained accordingly at desired levels. It was observed that the maximum degradation of acenaphthene by $\mathrm{Ba}$ at $\mathrm{pH} 9$ was $81.49 \%$ whereas in case of Ha, the maximum degradation was observed to be $60.3 \%$ at $\mathrm{pH} 7$ (Fig.4). It may be referred that $\mathrm{Ba}$ could grow at higher $\mathrm{pH}$ and so the degradation efficiency increased at higher values of $\mathrm{pH}(\mathrm{pH}$ 9) but after that as $\mathrm{pH}$ increased, the organism cannot survived at the higher $\mathrm{pH}$ and as a result degradation of acenaphthene decreased. In case of $H a$, the organism was unable able to grow at higher $\mathrm{pH}$ and so the degradation decreased at $\mathrm{pH}$, higher than 7 .

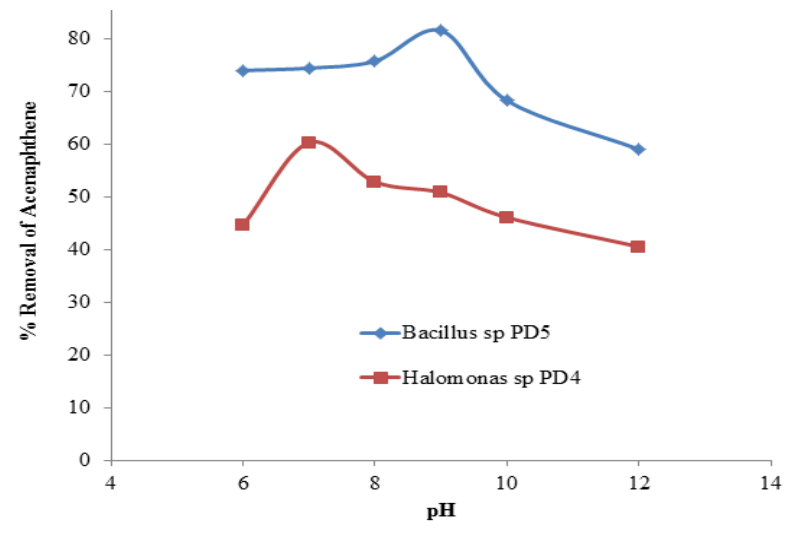

Figure 4. Comparison of the degradation of PAH (acenaphthene) by using Bacillus sp.PD5 and Halomonas sp.PD 4 at different $\mathrm{pH}$ after 14 days of degradation at $310 \mathrm{~K}$ temperature. 


\subsection{Effect of temperature}

To study the effect of temperature on the degradation of acenaphthene, experiment was conducted at various temperatures keeping all other parameters constant like $\mathrm{pH}$ and salinity ( $298 \mathrm{~K}, 303 \mathrm{~K}, 310 \mathrm{~K}$, $313 \mathrm{~K}, 318 \mathrm{~K})$. At $310 \mathrm{~K}$, results showed the significant degradation of acenaphthene by $B a$. Under such conditions, the percentage removal of acenaphthene was higher in case of $\mathrm{Ba}(63.94 \%)$ than Ha $(49.25 \%)$ after 7 days at $310 \mathrm{~K}$. At temperature 298K, $\mathrm{Ha}$ strain showed degradation of acenaphthene around $22 \%$ more than $B a$ [Fig.5].The reason may be that at $310 \mathrm{~K}$ temperature, these two micro-organisms were able to grow higher and as acenaphthene was only the carbon source in this case, the degradation of acenaphthene was higher at this temperature.

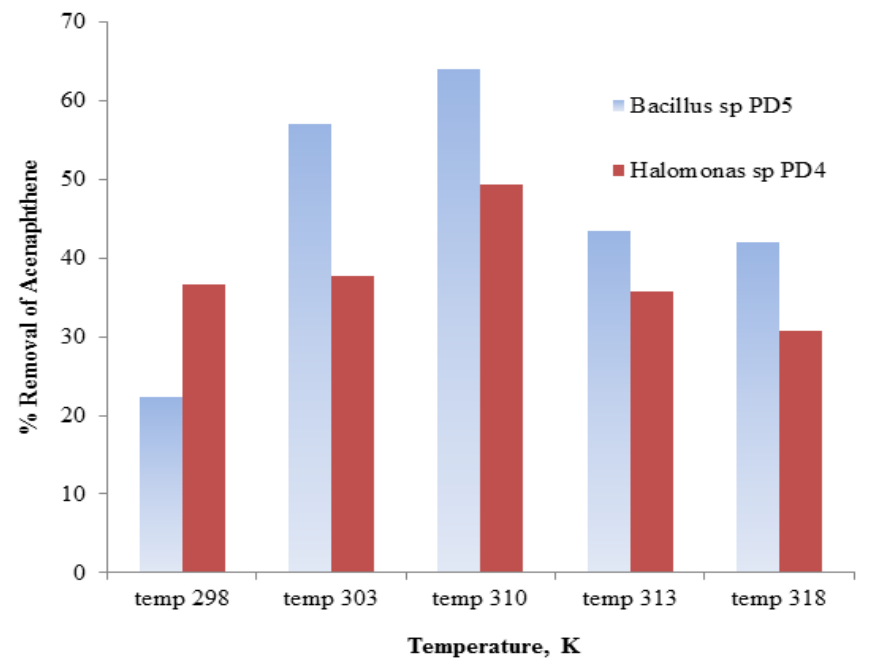

Figure 5. Comparison of the degradation on PAH (acenaphthene) by using Bacillus sp PD5 and Halomona sp. $P D_{4}$ at various temperatures after 7 days.

\subsection{Effect of agitation speed}

In this study, keeping all the parameters constant, the agitation speed was differed (80, $120,150 \mathrm{rpm})$. At these different agitation speed, at $80 \mathrm{rpm}$ and $150 \mathrm{rpm}, \mathrm{Ha}$ PD4 showed significantly greater removal of acenaphthene than $B a$. But at $120 \mathrm{rpm}$, removal of acenaphthene by $B a$ was greater than $H a$. Maximum degradation of acenaphthene by $\mathrm{Ba}$ and $\mathrm{Ha}$ PD4 were detected at $120 \mathrm{rpm}$ and $150 \mathrm{rpm}$ respectively [Fig.6].

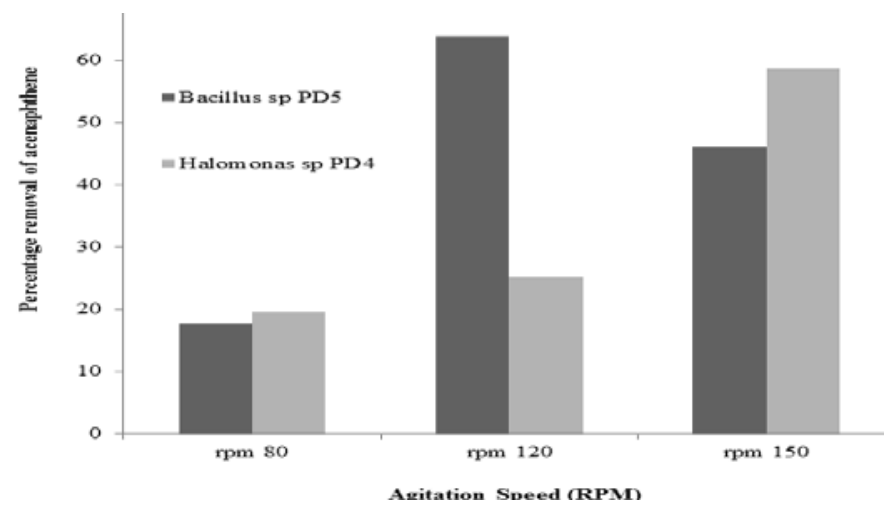

Figure 6. Comparison of the degradation on PAH (acenaphthene) by using Bacillus sp. PD5 and Halomonas sp. $P D_{4}$ at different speed of agitation after 7 day. 


\subsection{Neural network training}

In this study, inoculum volume $(\% \mathrm{w} / \mathrm{w})$, treatment time $(\mathrm{min})$, Temperature $(\mathrm{K})$ and $\mathrm{pH}$ as dependent variables were selected as input dependent variables to the neural network. The \% degradation of acenaphthene was selected as output variable. The best model would be selected which showed coefficient correlation $(\mathrm{R})$ near to 1 for the prediction of experimental results using the theoretical developed model by ANN. The experimental results were tested in different ANN structure. 'POSLIN' linear transfer function was selected in this case as input hidden layer mapping and "PURELIN" was chosen as hidden layer for the output layer mapping. It was observed (Table 1a and 1b) that Levenberg - Marquardt back propagation (LMB) showed the higher correlation coefficient value in both cases than other algorithm such as Resilient back propagation, Conjugate gradient back propagation, gradient descent (Fig.7a, Fig.7b and Table.1) which signified the reliability of the LMB model with the experimental results in both cases.

Table 1a. Trial and Error method for Bacillus sp. PD5 using ANN analysis:

\begin{tabular}{l|cccc}
\hline \multicolumn{1}{c|}{ Algorithm for hidden Layer } & $\begin{array}{c}\text { Function for } \\
\text { output layer }\end{array}$ & $\begin{array}{c}\text { Transfer } \\
\text { Function }\end{array}$ & $\begin{array}{c}\text { Transfer } \\
\text { Function }\end{array}$ & $\begin{array}{c}\text { Correlation } \\
\text { coefficient }(R)\end{array}$ \\
\hline $\begin{array}{l}\text { Levenberg - Marquardt } \\
\text { backpropagation }\end{array}$ & Trainlm & Poslin & Purelin & 0.972 \\
\hline Resilient backpropagation & Trainrp & Poslin & Purelin & 0.954 \\
\hline $\begin{array}{l}\text { Conjugate gradient backpropagation } \\
\text { with Polak-Ribiere updates }\end{array}$ & Traincgp & Poslin & Purelin & 0.976 \\
\hline $\begin{array}{l}\text { Scaled conjugate gradient } \\
\text { backpropagation }\end{array}$ & Trainscg & Poslin & Purelin & 0.794 \\
\hline $\begin{array}{l}\text { Gradient descent with momentum } \\
\begin{array}{l}\text { and adaptive learning rate } \\
\text { backpropagation }\end{array}\end{array}$ & Traingdx & Poslin & Purelin & 0.778 \\
\hline
\end{tabular}

Table 1b. Trial and Error method for Halomonas sp. PD4 using ANN analysis

\begin{tabular}{l|cccc}
\hline \multicolumn{1}{c|}{ Algorithm for hidden Layer } & $\begin{array}{c}\text { Function for } \\
\text { output layer }\end{array}$ & $\begin{array}{c}\text { Transfer } \\
\text { Function }\end{array}$ & $\begin{array}{c}\text { Transfer } \\
\text { Function }\end{array}$ & $\begin{array}{c}\text { Correlation } \\
\text { coefficient }\end{array}$ \\
(R)
\end{tabular}




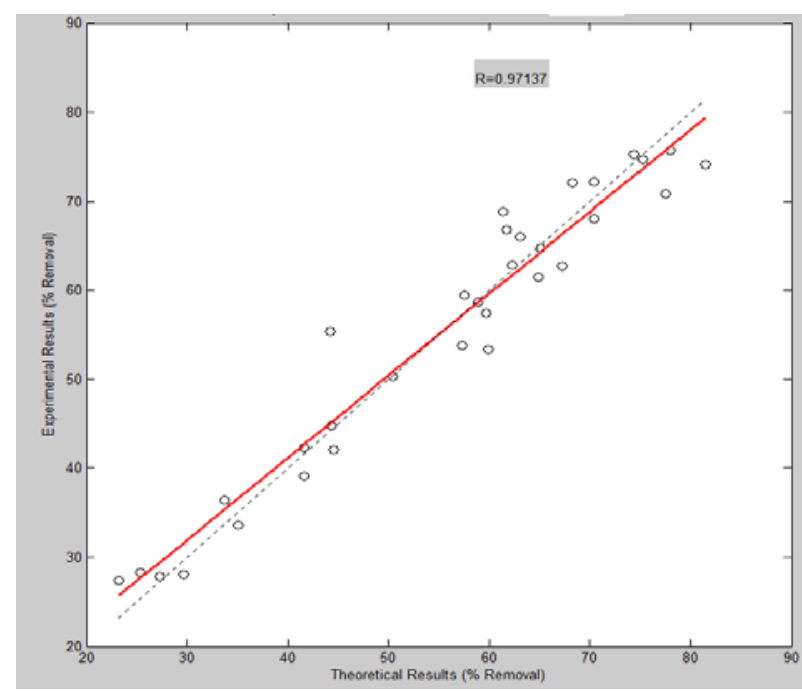

Figure 7a. Theoretical (ANN) results vs Experimental results of the ANN analysis for the degradation of acenaphthene using Bacillus sp.PD5

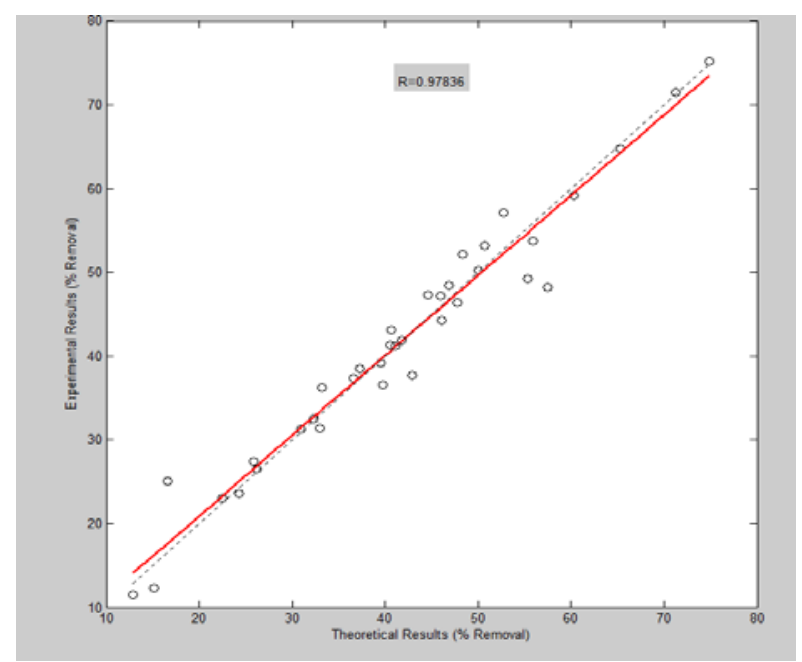

Figure 7b. Theoretical (ANN) results vs Experimental results of the ANN analysis for the degradation of acenaphthene using Halomonas sp. PD4.

\subsection{Validation of ANN model}

Tables $2 \mathrm{a}$ and $2 \mathrm{~b}$ showed the error analysis between developed model with the experimental data and it was observed that the \% error between the developed and experimental model was very low and the error was much more lower in case of model developed for the degradation using $H a$ which signified that the predictive ANN model significantly satisfied the experimental results at any point of time using both the micro-organisms.

Table 2a: Error analysis of experimental and ANN model of Bacillus sp. PD5

\begin{tabular}{c|ccc}
\hline Sl No. & Experimental Result & ANN Model & \% Error \\
\hline 1 & 35.07 & 33.44565 & -4.8566786 \\
2 & 44.17 & 43.33696 & -1.9222473 \\
3 & 65.07 & 66.05435 & 1.49020898 \\
4 & 81.49 & 83.90217 & 2.87498381 \\
\hline
\end{tabular}

Table 2b: Error analysis of experimental and ANN model of Halomonas sp. PD4

\begin{tabular}{r|rrr}
\hline Sl No. & Experimental Result & ANN Model & \% Error \\
\hline 1 & 25.124 & 24.29583 & -3.40868 \\
2 & 49.2512 & 49.42833 & 0.358364 \\
3 & 52.911 & 53.24063 & 0.619123 \\
4 & 57.404 & 57.92083 & 0.89231 \\
\hline
\end{tabular}

\section{Conclusion}

Both the strains Bacillus sp PD5 and Halomonas sp PD4. were isolated from two different sources. It was observed that both organisms had potent ability to degrade acenaphthene, used as sole source of 
carbon. In the present study, it can be suggested that as parameters mentioned before and as biological role of oxidation of acenaphthene, Bacillus sp PD5. can follow the suggested metabolic pathway leading to TCA whereas in case of Halomonas sp. PD4, though the strain can utilize acenaphthene but not as high as previous one.In the comparative study, it was found Bacillus sp PD5could degrade maximum acenaphthene (20\% more) than the Halomonas sp. PD4 strain. The reason may be that the various intermediate metabolites with dead end products of acenaphthene during metabolising process may produce due to some non-specific reaction. These may eventually results in reducing the rate of utilisation of the source of carbon. Even other factors like salinity, $\mathrm{pH}$, temperature might have decreased the microbial activity of Halomonas sp. PD4 and this may affect the rate of degradation of acenaphthene in case of Halomonas sp. PD4 strain resulting in a comparatively lower rate of utilisation of acenaphthene with the chosen parameters concern than Bacillus sp. PD5. The ANN analysis was performed to determine the optimum degradation of acenaphthene using two micro-organisms and it was observed that the developed ANN model satisfied the experimental results.

Acknowledgments. The authors would like to thank the Ministry of Earth Science (MOES) [MOES/36/OOIS/EXTRA/6/2013], Government of India, for providing financial support in undertaking this project.

\section{References}

1. S.J Geetha., S J. Joshi, K Shailesh, Isolation and characterization of hydrocarbon degrading bacterial isolate from oil contaminated sites, APBCEE Procedia,5, pp. 237-238, 2013.

2. W.Xue, D.Warshawsky, Metabolic activation of polycyclic and heterocyclic aromatic hydrocarbons and DNA damage: a review. Toxicology and Applied Pharmacology, 206, pp. 73-93, 2005.

3. J.V Pothuluri, C.E Cerniglia,. Microbial metabolism of polycyclic aromatic hydrocarbons, In: Chaundry GR (ed.), Biological degradation and bioremediation of toxic chemicals, Dioscorides Press, Portland, Oreg. Pp.92-124, 1994.

4. K. C.Jones, J. A Stratford, K. S. Waterhouse, E. T Furlong, W Giger, R. A Hites, C.Schaffner, A. E. Johnston, Increases in the polynuclear aromatic hydrocarbon contenet of an agricultural soil over the last century. Environmental Science and Technology, Vol. 23, pp. 95-101, 1989a.

5. K.C., Jones, J.A Stratford, P.Tidridge, K. S. Waterhouse, Polynuclear aromatic hydrocarbons in an agricultural soil: long-term changes in profile distribution. Environmental Pollution, Vol. 56, pp. 337 -351,1989b.

6. S. C. Wilson, K. C Jones, Bioremediation of soil contaminated with polynuclear aromatic hydrocarbons (PAHs): a review. Environmental Pollution. Vol. 81, pp. 229-249, 1993.

7. L.H Keith, W.A.Telliard, Priority pollutants I-a perspective view. Environmental Science \& Technology Vol. 13, pp. 416-42, 1979.

8. C.E Cerniglia, Degradation of polycyclic aromatic hydrocarbons. Biodegradation, Vol. 3, pp. 351-368, 1992

9. M. J .Schocken, D.T Gibson, Bacterial oxidation of the polycyclic aromatic hydrocarbons acenaphthene and acenaphthylene. Applies Environmental Microbiology, Vol.48, pp.10-16, 1984.

10. M Windholz, S Budavari, R.Blumetti, E.Otterbein, An encyclopedia of chemicals, drugs, and biologicals. In: O'Neil, M.J., Hechelman, P.E., Koch, C.B., Roman, K.J. (Eds.), The Merck Index, tenth ed. Merck and Co. Inc., Rahaway, NJ, 1983.

11. K.Nam, W. Rodriguez, J.J., Kukor, Enhanced degradation of polycyclic aromatic hydrocarbons by biodegradation combined with a modified Fenton reaction,, Chemosphere, Vol. 45, pp. 11-20, 2001.

12. L.H Zhang, P.J Li, Z.Q Gong, X.M Li, Photocatalytic degradation of polycyclic aromatic hydrocarbons on soil surfaces using TiO2 under UV light, Journal of Hazardous Materials. Vol. 158, pp. 478-484, 2008.

13. L Yu, X Tu, Y Wang, Y Chi, J,Yan, Destruction of acenaphthene, fluorine, anthracene, and pyrene by a dc gliding arc plasma reactor, Journal of Hazardous Materials. Vol. 180, pp. 449-455, 2010

14. K Malatova., Isolation and characterization of hydrocarbon degrading bacteria from environmental habitats in western New York state, Master's Thesis in Chemistry, 2005; Department of Chemistry, Rochester Institute of Technology, Rochester, NY.

15. M. M R. Abed, Assad Al-Thukair, D de Beer : Bacterial diversity of a cyanobacterial mat degrading petroleum compounds at elevated salinities and temperature. FEMS Microbiological Ecology, Vol. 57, pp.290-301, 2006. 
16. H P Zhaoa, Q S Wua, L Wanga, X T Zhaoa, H W Gaoa: Degradation of phenanthrene by bacterial strain isolated from soil in oil refinery fields in Shanghai China. Journal of Hazardous Materials, Vol. 164, pp. 863-869, (2009).

17. S.Y Yuan, S.H Wei., B.V Chang. Biodegradation of polycyclic aromatic hydrocarbons by a mixed culture. Chemosphere, Vol. 41, pp. 1463-1468, (2000).

18. K Das, AK Mukherjee, Differential utilization of pyrene as the sole source of carbon by Bacillus subtilis and Pseudomonas aeruginosa strain; role of biosurfactants in enhancing bioavailability. Journal of Applied Microbialogy, Vol. 102, pp. 195-203, 200).

19. S M Dastgheib, M A Amoozegar, K Khajeh, M Shavandi, A Ventosa, Biodegradation of polycyclic aromatic hydrocarbons by a halophilic microbial consortium, Applied Microbiology \& Biotechnology, Vol. 95,pp. 789-798, 2012 .

20. B Boldrin., A.Thiem, C Fritzsche., Degradation of phenanthrene, fluorine, fluoranthene, and pyrene by Mycobacterium sp., Applied Environmental Microbialogy,Vol. 59, pp. 19-27, 1993.

21. S Parviz, S S Abbas, C A Hossein, Biodegradation of polycyclic Aromatic Hydrocarbons by Aerobic Mixed Bacterial Culture Isolated from Hydrocarbon Polluted Soils, Iranian Journal of Chemistry and chemical Engineering, Vol. 25 no. 3, pp. 73-77, 2006.

22. S.A Churchill, J.P., Harper, P.F Churchill, Isolation and characterization of a Mycobacterium sp. capable of degrading three and four-ring aromatic and aliphatic hydrocarbons, Applied and Environmental Microbiology, Vol 65, pp. $549-552,1999$.

23. O Pinyakong, H Habe, A Kouzuma, H. Nojiri, H Yamane, T Omori, Isolation and characterization of genes encoding polycyclic aromatic hydrocarbon dioxygenase from acenaphthene and acenaphthylene degrading Sphingomonas sp. strain A4. FEMS Microbiology Letters, Vol 238, pp. 297-305, 2004.

24. D Ghosal, A Dutta, J Chakraborty, S Basu, T K Dutta., Characterization of the metabolic pathway involved in assimilation of acenaphthene in Acinetobacter sp. strain AGAT-W, Research Microbiology, Vol. 164 , pp. 155$163,2013$.

25. T Komatsu, T Omari, T Kodama, Microbial degaration of the polycyclic aromatic hydrocarbons acenaphthene and acenaphthylene by a pure bacterial culture. Bioscience Biotechnology and Biochemistry, Vol. 57, pp. 864$865,1993$.

26. P.J Chapman,., Degradation mechanisms. In: Bourquin, A.W., Pritchard, P.H. (Eds.), Proceedings of the Workshop: Microbial Degradation of Pollutants in Marine Environments. U.S. Environmental Protection Agency, Gulf Breeze, pp. 28-66, 197).

27. S.A Selifonov., A.V Slepen'kin., V.M Adanin, G.M Grechkina, I.I Starovoitov.,.Acenaphthene catabolism by strains of Alcaligenes eutrophus and Alcaligenes paradoxus. Microbiology, Vol. 62, pp. 85-92,1993.

28. P Das, P Banerjee, A Jaman, P Bhattacharya, Biodegradation of two Azo dyes using Dietzia sp. PD1: Process Optimization using Response Surface Methodology and Artificial Neural Network, Desalination \& Water Treatment, Vol. 57 no. 16, pp. 7293-7301, 2016.

29. B Kumari, S.N Singh, F Deeba, M Sharma, V Pandey , D.P Singh.,Elucidation of Pyrene Degradation Pathway in Bacteria. Advance in Bioresearch, Vol. 2, pp. 151-160, 2013.

30. S Chakraborty, S Chowdhury, P Das Saha, Artificial neural network (ANN) modelling of dynamic adsorption of crystal violet from aqueous solution using citric acid modified rice (Oryza sativa) straw as adsorbent, Clean Technologies and Environmental Policy, Vol. 15, pp. 255-264, 2013.

31. K Sinha, S Chowdhury, P Das Saha, S Datta, Modeling of microwave-assisted extraction of natural dye from seeds of Bixa orellana (Annatto) using response surface methodology (RSM) and artificial neural network (ANN), Industrial Crops and Products, Vol. 41, pp. 165-171, 2013.

32. S Chowdhury, P Das Saha, Artificial neural network (ANN) modeling of adsorption of methylene blue by $\mathrm{NaOH}$-modified rice husk in a fixed-bed column system, Environmental Science and Pollution Research, Vol. 20, pp. 1050-1058, 2013.

33. K Sinha, P Das Saha, S Datta, Response surface optimization and artificial neural network modeling of microwave assisted natural dye extraction from pomegranate rind, Industrial Crops and Products, Vol. 37, pp. 408-414, 2012.

34. P Das Saha, S Dutta, Mathematical modelling of biosorption of safranin onto rice husk in a packed bed column using artificial neural network analysis, Desalination and WaterTreatment, Vol.41, pp. 308-314, 2012. 
35. K.V Kumar, K Porkodi., Modelling the solid-liquid adsorption process using Artificial Neural Networks trained by pseudo second order kinetics, Chemical Engineering Journal, Vol. 148 no. 1, pp. 20-25, 2009. 